\title{
Severity of Allergic Rhinitis and Body Mass Index: Is There Any Correlation?
}

\author{
Gomathi Paramasivam, ${ }^{1}$ Fifi Veronica, ${ }^{2}$ Yovi Yoanita ${ }^{3}$ \\ ${ }^{1}$ Faculty of Medicine Universitas Padjadjaran, ${ }^{2}$ Department of Anatomy and Cell Biology \\ Faculty of Medicine Universitas Padjadjaran, ${ }^{3}$ Department of Public Health Faculty of Medicine \\ Universitas Padjadjaran
}

\begin{abstract}
Background: Allergic rhinitis is the inflammation of the nasal mucosa. It will be resulting in nasal itching, sneezing, discharge, or blockage which occurs for more than an hour on most days. Allergens such as plant pollens, fungi, animal allergens, and dust mites are the factors which initiate allergic rhinitis. There are many risk factors for allergic rhinitis, such as family history of atopic disease, asthma, age, gender and others. Besides, overweight is also considered one of the risk factors for developing allergic rhinitis. Thus, this study was conducted to investigate the correlation between allergic rhinitis and body mass index.

Methods: This study involved a cross-sectional analytic study. Seventy three respondents both male and female medical students of Universitas Padjadjaran completed a questionnaire, and had their height and weight measured by a trained researcher. This study was carried out from September to October 2015. Statistical analyses were performed included the Rank Spearman test.

Results: There was no significant relationship between allergic rhinitis and body mass index.

Conclusions: There is no correlation between severity of allergic rhinitis and body mass index. [AM].2017;4(1):20-4]
\end{abstract}

Keywords: Allergic rhinitis, body mass index, severity

\section{Introduction}

Allergic rhinitis is the inflammation of the nasal mucosa which is mediated by immunoglobulin E. It is triggered by allergens such as pollen, dust mite, animal dander and mould spores. ${ }^{1}$ Allergic rhinitis occurs when inhaled allergens interact with IgE antibodies on cells in the airway which initiate Hypersensitivity type $1 .^{2}$ The symptoms of allergic rhinitis are nasal congestion, rhinorrhea, sneezing, nasal itching, and nasal obstruction. ${ }^{3}$ It is one of the most common types of rhinitis and effect $10-20 \%$ of populations and there are evidence that the prevalence of allergic rhinitis is increasing. ${ }^{4}$

Previously, allergic rhinitis has been categorized as seasonal or perennial but, not all patients fit into this classification. As an example, some allergic triggers, such as pollen, may be seasonal in cooler climates, but perennial in warmer climates. Thus, it is classified based on its severity as mild, moderate-severe by allergic rhinitis and its impacts on Asthma (ARIA). ${ }^{5}$ The ARIA also classified the allergic rhinitis into intermittent and persistence based on onset of the disease. ${ }^{5}$

Allergic rhinitis is a disease that not only impairs ones quality of life but also disturb sleep and work. ${ }^{6}$ Allergic rhinitis is a burden for both paediatric and adult patients not only because of the physical symptoms but also due to the emotional and social effects. ${ }^{7,8}$ There are many complications of this disease which effect physically and psychosocially. The comorbidities of this disease are asthma, otitis media with suppurative, rhinosinusitis, and sleep disturbance. Allergic rhinitis is not only causing physical problems to nose and lower

Correspondence: Gomathi Paramasivam, Faculty of Medicine, Universitas Padjadjaran, Jalan Raya Bandung-Sumedang Km.21, Jatinangor, Sumedang, Indonesia, Phone: +6287827997081 Email: gomathiparamasivam93@gmail.com 
airway but also causes psychosocial problems including those in learning and cognitive processes and in missing work or school. Thus, it is very important to understand the disease and find ways to decrease the occurrence of it. ${ }^{9}$

There are many risk factors for allergic rhinitis, such as family history of atopic disease, asthma, age, gender and others. Besides, overweight is also considered one of the risk factors for developing allergic rhinitis..$^{10,11}$

According to the WHO since 2008, more than 1.4 million adults were overweight. The WHO categorizes a person into underweight, normoweight, overweight and obese based on Body Mass Index (BMI). Those who are less than BMI of 17.5 is categorized underweight, those in between BMI of 17.5 to less than 25 is normoweight, those more than or equal to BMI of 25 is considered overweight, while those who are more than or equal to BMI of 30 is considered obese. ${ }^{12}$

A few studies have been conducted to identify the correlation of atopic disease with BMI. Results of the studies prove there are correlations between allergic rhinitis and BMI. ${ }^{10,11}$ But the studies are conducted overseas such as Australia and Germany. ${ }^{11}$ There are no relevant data about the correlation between allergic rhinitis and obesity in Asian countries like Indonesia. Some studies do not find any relevant data regarding the correlation between allergic rhinitis and BMI which are carried out in school-aged children. ${ }^{13}$ So, this study was aimed to investigate the correlation between allergic rhinitis and BMI among regular medical students of Universitas Padjadjaran.

\section{Methods}

Participants of the study were recruited from regular medical students of Universitas Padjadjaran. To make sure the respondent was eligible to be recruited to the study an inclusion criteria was determined. A total sampling method was used to recruit participants who fulfil the inclusion criteria.
The inclusion criteria for this study were the participants must be regular medical students of Universitas Padjadjaran, can be both male and female, Students who had been diagnosed with allergic rhinitis by a physician based on the questionnaire, physical exam and the results of skin prick test, students who presented with or without co-morbidities such as asthma, sinusitis, conjunctivitis, otitis media, atopic dermatitis and other allergies, students who agreed to participate in this study by signing the informed consent form.

This study is a cross-sectional analytic study. A self-report questionnaire was completed by each participant, and body weight and height were measured. This study was conducted at Universitas Padjadjaran from September to October 2015. Ethics approval was granted by the Health Research Ethics Committee, Dr. Hasan Sadikin General Hospital, Bandung. Furthermore, all participants provided informed consent prior to involvement in the study.

Questionnaires about the severity of Allergic Rhinitis based on the American Academy of Allergy, Asthma, and Immunology (AAAAI), the American College of Allergy, Asthma, and Immunology(ACAAI), and the Joint Council of Allergy, Asthma, and Immunology which had been validated were distributed to the respondents .

The BMI was calculated by dividing weight in kilograms by the square of height in meters $\left(\mathrm{kg} / \mathrm{m}^{2}\right)$. Based on his/her BMI, an individual was classified into normal (BMI ranged from 18.5 to $24.9 \mathrm{~kg} / \mathrm{m}^{2}$ ), overweight (BMI 25-29.9 $\mathrm{kg} / \mathrm{m} 2)$, or obese (BMI $>30 \mathrm{~kg} / \mathrm{m}^{2}$ ).

The study used the Visual Analog Scale (VAS) to measure the severity of Allergic Rhinitis. The scale consists of 7 numbers and the patient had to decide the number according to their severity. Severity of Allergic Rhinitis can be divided into two, mild and moderate-severe. Mild is less than number 4 in VAS, while moderate-severe is number 4 or more in VAS.

The correlation between BMI and severity of allergic rhinitis was analysed after the

Table 1 Characteristic of Respondent Based on Gender

\begin{tabular}{llcc}
\hline & Gender & Percentage\% & Percentage\% \\
\hline Male & 39.73 & 39.73 \\
Female & 60.27 & 60.27 \\
Total & 100 & 100 \\
\hline
\end{tabular}


Table 2 Distribution of Body Mass Index (BMI)

\begin{tabular}{llcc}
\hline \multicolumn{1}{c}{ Body Mass Index (BMI) } & & Frequency & Percentage\% \\
\hline Underweight & 4 & 5.48 \\
Normal & 58 & 79.45 \\
Overweight & 11 & 15.07 \\
Total & 73 & 100 \\
\hline
\end{tabular}

Table 3 Severity Classification of Allergic Rhinitis

\begin{tabular}{|c|c|c|}
\hline Severity of Allergic Rhinitis & Frequency & Percentage \% \\
\hline Severe Intermittent & 18 & 24.66 \\
\hline Mild Intermittent & 42 & 57.53 \\
\hline Severe Continuous & 12 & 16.44 \\
\hline Mild Continuous & 1 & 1.37 \\
\hline Total & 73 & 100 \\
\hline
\end{tabular}

respondents were divided into groups based on BMI and the level of severity. The cut-off point of BMI used in the analysis was $25 \mathrm{~kg} /$ $\mathrm{m}^{2}$. Respondents were categorized into two levels of severity based on the Visual Analog Scales (VAS) for the severity of the total symptoms. Participants scoring three or less on the VAS were categorized as having mild symptoms, while participants scoring more than three were categorized as having nonmild symptoms. Data obtained from the VAS of global assessment of nasal and non-nasal symptoms were analysed using inferential statistics with the level of significance set at 0.05 . The correlation between severity of allergic rhinitis and body mass index was analysed using Rank Spearman test.

\section{Results}

Furthermore, the results were analysed through descriptive analysis of characteristics of allergic rhinitis based on gender among regular medical students of Universitas Padjadjaran which were shown in frequency distribution and association tables.

According to the characteristic of respondent based on gender most of the respondent is female. The ratio between female to male is 3:2 (Table 1).

The majority of respondents as much as $79.45 \%$ had a normal BMI category, the second highest frequency was as much as $15.07 \%$ of the students were categorized overweight, and the least students as much as $5.48 \%$ were categorized underweight (Table2).

The majority of the respondents had a mild intermittent allergic rhinitis which was $57.53 \%$, the second highest frequency was severe intermittent allergic rhinitis which was $24.66 \%$, followed by students who had severe continuous allergic rhinitis which was $16.44 \%$

Table 4 Relationship between BMI and Severity of Allergic Rhinitis

\begin{tabular}{|c|c|c|c|c|c|c|c|c|c|c|c|}
\hline \multirow{3}{*}{ BMI } & \multicolumn{8}{|c|}{ Severity Of Allergic Rhinitis } & & & \multirow{3}{*}{ p-value } \\
\hline & \multicolumn{2}{|c|}{$\begin{array}{c}\text { Severe } \\
\text { Intermittent }\end{array}$} & \multicolumn{2}{|c|}{$\begin{array}{c}\text { Mild } \\
\text { Intermittent }\end{array}$} & \multicolumn{2}{|c|}{$\begin{array}{c}\text { Severe } \\
\text { Continuous }\end{array}$} & \multicolumn{2}{|c|}{ Mild Continuous } & \multicolumn{2}{|c|}{ Total } & \\
\hline & $\mathrm{F}$ & $\%$ & $\mathrm{~F}$ & $\%$ & $\mathrm{~F}$ & $\%$ & $\mathrm{f}$ & $\%$ & $\mathrm{f}$ & $\%$ & \\
\hline Underweight & 1 & 25.0 & 3 & 75.0 & 0 & 0.0 & 0 & 0.0 & 4 & 100 & \\
\hline Normal & 11 & 19.0 & 34 & 58.6 & 12 & 20.7 & 1 & 1.7 & 58 & 100 & $00\ulcorner 1 *$ \\
\hline Overweight & 6 & 54.5 & 5 & 45.5 & 0 & 0.0 & 0 & 0.0 & 11 & 100 & 0.051 \\
\hline Total & 18 & 24.7 & 42 & 57.5 & 12 & 16.4 & 1 & 1.4 & 73 & 100 & \\
\hline
\end{tabular}

Note: *Using Rank Spearman 
and the least students had mild continuous allergic rhinitis which was 1.37\% (Table 3).

Moreover, out of 4 students who had a BMI category of underweight mostly had mild intermittent allergic rhinitis which was $75 \%$. Out of 58 students who had normal BMI category, mostly as much as $58.6 \%$ had mild intermittent allergic rhinitis and among 11 students who had BMI categorized under overweight, mostly as much as $54.5 \%$ had severe intermittent allergic rhinitis. The results of correlation analysis, obtained by the $p$-value of $0.051>0.05$, indicated that there was no significant relationship between body mass index and severity of allergic rhinitis among regular medical students of Universitas Padjadjaran batch 2011.

\section{Discussion}

Results of the correlation between BMI and severity of allergic rhinitis among regular medical students of Universitas Padjadjaran can be referred to Table 4. From the data analysis using the Rank Spearman test, the researcher accepted the null hypothesis ( $p$ $>0.05$ ) and it was now known that basically there was no significant correlation between body mass index and severity of allergic rhinitis among regular medical students of Universitas Padjadjaran.

There were many factors that could contribute to this result. The data for this study was mainly obtained from students who mostly had mild type of allergic rhinitis. Therefore, it was hard to see the correlation between the severity of allergic rhinitis and body mass index. Besides, most of the respondent was categorized under normal weight. Thus, it was hard to see the correlation between the variables.

The result was not significant, meaning that basically there was no correlation between body mass index and severity of allergic rhinitis among regular medical students of Universitas Padjadjaran. Hence, based on the hypothesis, it was assumed that there was significant relationship between body mass index and severity allergic rhinitis. According to a study conducted by Alrasyid et al. ${ }^{11}$ there is significant relationship between severity of allergic rhinitis and body mass index. The theory from that study might not be applicable in West Java especially in Bandung due to some reasons. The previous study was conducted in Australia; perhaps th difference in environment and climate between Indonesia and Australia can cause the difference in the results. Besides, the study population in the previous study was patients from the immunology department but in this studythe patients were medical students who were suffering from allergic rhinitis. The diagnosis for the subjects is made from history taking, physical exam and skin prick test which may be less accurate to diagnose those who are not in active phase during the examination. Additionally, based on a study by Mutious et al. ${ }^{14}$, there is no significant relation between atopic disease and BMI in children.

As the study population was only the regular medical students of Universitas Padjadjaran, the researcher could only take the number of students who were positive for allergic rhinitis. Thus, only 73 students were used in this study which was not sufficient to prove the theory that there was association between severity allergic rhinitis and BMI. Besides, the study population was medical students of Universitas Padjadjaran. Most of the student's age was averaged 19-22 years. Therefore, it influenced the severity of allergic rhinitis. This study also needed the respondents to answer the questionnaire which might lead to the recall bias. Lastly, the time allocated to carry out this thesis was very limited.

Based on the data analysis and discussion, the conclusion is that there is no significant relationship between BMI with the severity of allergic rhinitis.

\section{References}

1. Walls RS, Heddle RJ, Tang MLK, Basker BJ, Solley GO, Yeo GT. Optimising the management of allergic rhinitis; an Australian Perspective. Med J Aust. 2005;182(1):28-33.

2. Plaut $\mathrm{M}$, Valentine MD. Allergic rhinitis. $\mathrm{N}$ Engl J Med. 2005;353(18):1934-44.

3. Tran NP, Vickery J, Blaiss MS. Management of rhinitis: allergic and non-allergic. Allergy Asthma Immunol Res. 2011;3(3):148-56.

4. Small P, Kim H. Allergic rhinitis. Allergy Asthma Clin Immunol. 2011:7(Suppl 1);S3

5. WHO. Chronic rhinitis and sinusitis: allergic rhinitis and sinusitis. 2014 [cited 2014 May 23]; Available from: http:// www.who.int/respiratory/other/Rhinitis_ sinusitis/en/.

6. Green RJ, Davis G. The burden of allergic rhinitis. Curr Allergy Clin Im. 2005;18(4):176-8.

7. Blaiss MS. Allergic rhinoconjunctivitis: burden of disease. Allergy Asthma Proc. 2007;28(4):393-7.

8. Eichler I, Soriano ES. Close collaboration 
between academia, industry and drug regulators is required in the development of allergen products for specific immunotherapy in children. Allergy. 2011;66(8):999-1004.

9. Bousquet J, Khaltaev N, Cruz AA, Denburg J, Fokkens WJ, Togias A, et al. Allergic Rhinitis and its Impact on Asthma (ARIA) 2008 update (in collaboration with the World Health Organization, GA(2)LEN and AllerGen). Allergy. 2008;63 Suppl 86:8-160.

10. van de Ven MO, van den Eijnden RJ, Engels RC. Atopic diseases and related risk factors among Dutch adolescents. Eur J Public Health. 2006;16(5):549-58.

11. Alrasyid H, McManus A, Mallon D, Nicholson C. Elevated body mass index is associated with severity of allergic rhinitis: results from a cross sectional study. Aust Med J. 2008;1(2):1-17

12. WHO. Obesity and overweight. 2013[cited 2014 May 23] Available from: http:// www.who.int/mediacentre/factsheets/ fs311/en/

13. Sidell D, Shapiro NL, Bhattacharyya N. Obesity and the risk of chronic rhinosinusitis, allergic rhinitis, and acute otitis media in school-age children. Laryngoscope. 2013;123(10):2360-3.

14. von Mutius E, Schwartz J, Neas LM, Dockery D, Weiss ST. Relation of body mass index to asthma and atopy in children: the National Health and Nutrition Examination Study III. Thorax. 2001;56(11):835-8. 